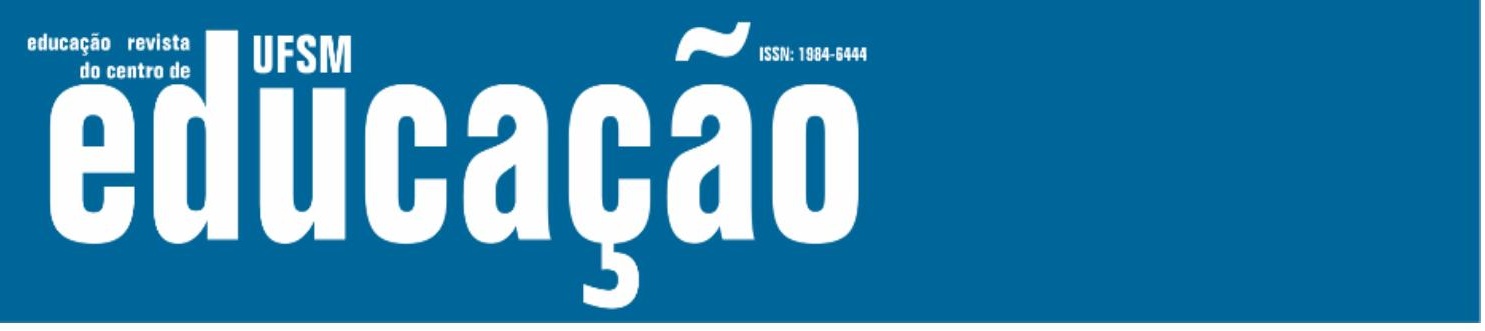

ISSN: 1984-6444 | http://dx.doi.org/10.5902/1984644445284

\title{
Sala de aula invertida: Emancipação de mestres e aprendizes à luz das ideias de Freire e Ranciére
}

\author{
Flipped classroom: Emancipation of masters and learned in the light of \\ the ideas of Freire and Ranciére
}

Luiz Maurício Bentim da Rocha Menezes

Professor doutor no Instituto Federal de Educação, Ciência e Tecnologia do Triângulo Mineiro (IFTM) Imbrmenezes@yahoo.com.br - http://orcid.org/0000-0003-4925-9876

Selma Maria de Oliveira

Mestranda Instituto Federal de Educação, Ciência e Tecnologia do Triângulo Mineiro (IFTM) selma.maria09@gmail.com - https://orcid.org/0000-0003-4829-4856

Recebido em 29 de maio de 2020

Aprovado em 11 de agosto de 2021

Publicado em 24 de fevereiro de 2022

\section{RESUMO}

Os autores Jacques Rancière e Paulo Freire em suas obras asseveravam sobre a importância da educação como uma prática de liberdade, sem hierarquização, que conduza os alunos para uma emancipação intelectual. Nossa reflexão é sobre a presença destes ideais na adoção da metodologia da Sala de Aula Invertida para respondermos de que forma o uso dessa estratégia contempla os preceitos destes pensadores, na perspectiva da emancipação, da igualdade das inteligências de alunos e professores. O objetivo geral do estudo é refletir criticamente sobre como a Sala de Aula Invertida contribui para a emancipação de alunos e professores à luz das ideias de Freire e Rancière, bem como identificar os pilares que dão sustentação à metodologia de inversão da aprendizagem e extrapolar a concepção tradicional do ofício de ser professor como um mero explicador. Infere-se que o objeto escolhido para estudo poderá abalizar a adoção desta nova metodologia, contribuindo para práticas pedagógicas que colaborem para a construção de uma educação emancipadora, igualitária, pautada em valores éticos e alicerces sólidos que permitam ao indivíduo não só estar no mundo, mas ser parte integrante dele, problematizando, reconhecendo-se e intervindo. A pesquisa tem uma abordagem qualitativa e procedimento bibliográfico, compondo uma tessitura de reflexões e considerações para confirmação ou não da hipótese inicial. Sua relevância centra-se na possibilidade de identificar na Sala de Aula Invertida, além de uma estratégia do uso da tecnologia a favor da aprendizagem, também um potencial para o exercício emancipatório de professores e alunos, na prática da igualdade das inteligências. Neste viés, será destacado o poder do diálogo, a relevância da dúvida e da curiosidade como pontes para o conhecimento, apontando que as convicções de Freire e Rancière são 


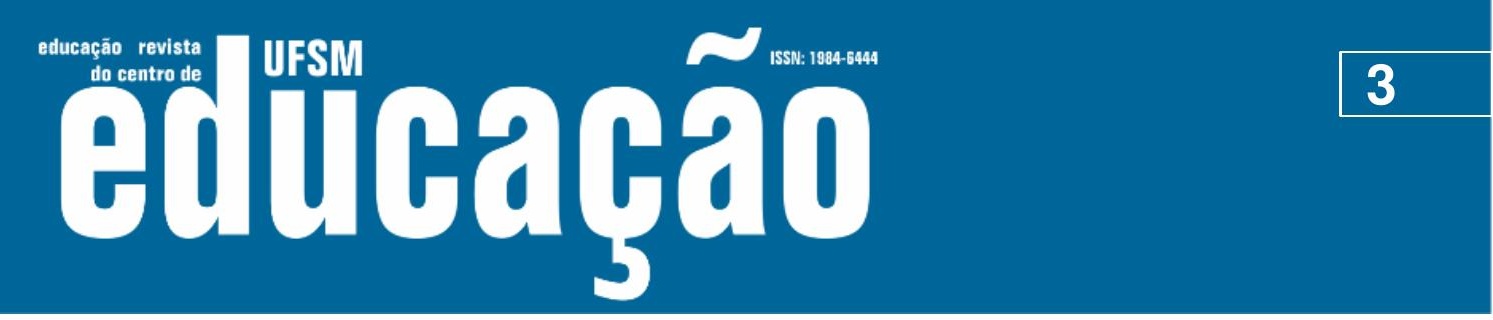

ISSN: 1984-6444 | http://dx.doi.org/10.5902/1984644445284

buscam, por meio de estratégias diferenciadas, desenvolver habilidades e competências que colaborem para a formação humana integrada, por meio da efetividade da aprendizagem.

Como o próprio nome já sugere Metodologias Ativas - MA pressupõem uma multiplicidade de caminhos, diversidade de ferramentas, técnicas e atividades pelas quais o sujeito aprende fazendo, colocando-se na posição de protagonista. No contexto da educação, MA define um conjunto de ações lógicas objetivando desenvolver nos alunos a capacidade de aprender novas competências, ocupando a centralidade do fazer pedagógico.

Segundo Cotta et al. (2012, p. 788), as metodologias ativas no processo de ensino e aprendizagem são estratégias pedagógicas com prática criticorreflexiva que permitem uma leitura e intervenção sobre a realidade. Essa metodologia favorece a interação entre alunos e professores e seus pares, valorizando a construção coletiva do conhecimento, a intervenção sobre a realidade e os múltiplos saberes, portanto, fomenta a aprendizagem significativa que ocorre quando

o aluno interage com o assunto em estudo - ouvindo, falando, perguntando, discutindo, fazendo e ensinando - sendo estimulado a construir o conhecimento ao invés de recebê-lo de forma passiva do professor. Em um ambiente de aprendizagem ativa, o professor atua como orientador, supervisor, facilitador do processo de aprendizagem, e não apenas como fonte única de informação e conhecimento (BARBOSA; MOURA, 2013, p.55).

A dinamicidade de como a informação circula em nossa sociedade não pode ser ignorada por educadores, pois faz parte das formas atuais de aprender e ensinar. $\mathrm{Na}$ proposta pedagógica apoiada nas Metodologias Ativas, os professores medeiam às atividades a fim de conduzir os estudantes para uma formação crítica, proporcionando situações do que será encontrado no cotidiano, visando antecipar e intervir a situações e problemas reais. Nesta perspectiva, "ativa", pode ser entendida como significativa, que conduz o aluno a pensar constantemente, no que está fazendo, com acesso a diferentes fontes de informações que poderão auxiliá-lo.

Assim, diversas técnicas de Metodologias Ativas vêm sendo discutidas, tais como: aprendizagem baseada em problemas, aprendizagem baseada em projetos, 


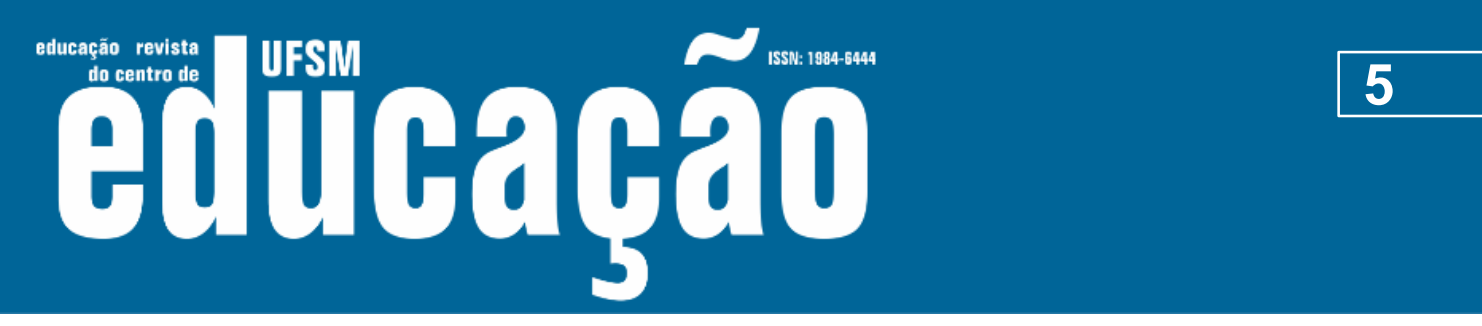

ISSN: 1984-6444 | http://dx.doi.org/10.5902/1984644445284

a relação discente e docente se dá de forma horizontal, mantendo uma linearidade, sobre isso declara Rancière:

\begin{abstract}
É assim que o mestre ignorante pode instruir tanto aquele que sabe quanto o ignorante verificando se ele está pesquisando continuamente. Quem busca, sempre encontra. Não encontra necessariamente aquilo que buscava menos ainda aquilo que é preciso encontrar. Mas encontra alguma coisa nova, a relacionar à coisa que já conhece [...]. O essencial é essa contínua vigilância, essa atenção que jamais se relaxa sem que venha a se instalar a desrazão em que excele tanto aquele que sabe quanto o ignorante. $O$ mestre é aquele que mantém o que busca em seu caminho, onde está sozinho a procurar e o faz incessantemente. (RANCIÉRE, 2010, p. 56-57)
\end{abstract}

Os conceitos sobre emancipação e igualdade de inteligência de Freire e Rancière são convenientes quando analisamos a metodologia da Sala de Aula Invertida como uma estratégia que permite a conversa sem barreiras entre alunos e professores, onde os primeiros são convocados a previamente estudar o conteúdo, apoiado por alguma tecnologia que os coloquem em contato com o tema e a problematização levantada pelo seu mestre. Os segundos, os professores, cabem o caminho de mediador, de planejar o percurso para que o aluno possa alcançar o conhecimento. Nessa metodologia, alunos e professores são sujeitos iguais, pois não há saber mais ou saber menos, a esse respeito Freire afirma:

E neste sentido que ensinar não é transferir conhecimentos, conteúdos nem forrar são ação pela qual um sujeito criador dá forma, estilo ou alma a um corpo indeciso e acomodado. Não há docência sem discência, as duas se explicam e seus sujeitos, apesar das diferenças que os conotam, não se reduzem à condição de objeto, um do outro. Quem ensina aprende ao ensinar e quem aprende ensina ao aprender. (FREIRE, 2002 p. 11)

O conceito de Sala de Aula Invertida começou a ser desenvolvido na década de 90 com os autores Eric Mazur, em "Peer instruction: User's manual" e Gregor Novak em "Just-in-time Teachin, todavia, sua popularização surgiu do termo "Flipped classroom", a partir da experiência de Aaron Sams e Jonathan Bergmann, autores estadunidenses que começaram a disponibilizar previamente 0 material a ser estudado aos alunos que por algum motivo não podiam assistir às aulas. $O$ procedimento adotado por Sams e Bergmann mostrou-se exitoso não somente para 


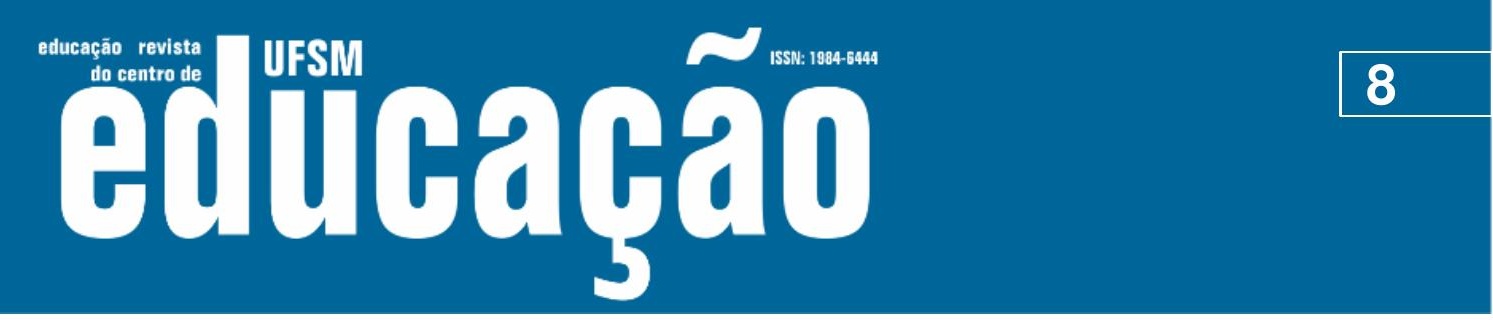

ISSN: 1984-6444 | http://dx.doi.org/10.5902/1984644445284

acreditam na igualdade das inteligências, no poder do diálogo, na relevância da dúvida e da curiosidade como pontes para o conhecimento, apontando que as convicções de Paulo Freire e Jacques Rancière são possíveis de concretização e estão presentes no desenvolvimento desta estratégia tão contemporânea. Neste panorama de relações em rede, de seres conectados e mercado profissional competitivo, faz-se necessário uma educação com estratégias diversificadas e criativas que provoquem mudanças para a construção de uma sociedade que saiba intervir na realidade.

\title{
A sala de aula invertida
}

O uso da tecnologia na educação é um novo domínio para a pedagogia que em seu próprio conceito traz a ideia de pluralidade, de inter-relação e de intercâmbio crítico entre saberes e conceitos desenvolvidos por diferentes pensadores. Um olhar para o público-alvo da educação refletirá a sociedade atual, plural e conectada e, nesse contexto, deparamo-nos com a árdua tarefa de ensinar. Os parâmetros curriculares nacionais - PCNs trazem que

\begin{abstract}
As novas tecnologias da comunicação e da informação permeiam o cotidiano independente do espaço físico e criam necessidades de vida e convivência que precisam ser analisadas no espaço escolar. A televisão, o rádio, as informáticas, entre outras, fizeram com que os homens se aproximassem por imagens e sons de mundos antes inimagináveis/ Os sistemas tecnológicos, na sociedade contemporânea, fazem parte do mundo produtivo e da prática social de todos os cidadãos, exercendo um poder de onipresença, uma vez que criam formas de organização e transformação de processos e procedimentos. (BRASIL, 2000, p.11-12)
\end{abstract}

No tempo em que as políticas educacionais impõem mudanças curriculares na educação básica, os profissionais que atuam neste nível de ensino são conclamados ao engajamento em práticas pedagógicas capazes de qualificar os conteúdos, dando sentido e significação aos objetos de aprendizagem estudados pelos alunos. A adoção da metodologia da Sala de Aula Invertida aponta ser uma alternativa e não simplesmente, mais um modismo, para melhorar a qualidade do ensino-aprendizagem nas instituições educativas. Assim, no uso desta metodologia, percebemos o potencial emancipador falado por Paulo Freire ao propiciar ao estudante conhecer, aprender e a fazer, intervindo na realidade; e de igualdade das inteligências para mestres e 


\section{Uism Eltothato

ISSN: 1984-6444 | http://dx.doi.org/10.5902/1984644445284

Notadamente, pode-se perceber que nessa metodologia o aluno ganha um papel de protagonista da aprendizagem, conforme Freire (2018), o conhecimento da realidade é indispensável ao desenvolvimento da consciência de si e, consequentemente, ao aumento do conhecimento do mundo. $\mathrm{O}$ ato de conhecer não se dá apenas na dicotomia entre objetividade e subjetividade, mas também na relação entre estes elementos na sua ação.

É isso que a Sala de Aula Invertida propõe: a conjugação de todos estes elementos, rompendo os limites impostos pelas paredes das salas de aula, buscando a autonomia como forma de consolidar o conhecimento, numa ação dialógica e proativa do educando. A realidade em que o sujeito está imerso não pode estar desvinculada de seu processo de conhecimento, pois partindo de uma filosofia de igualdade baseada na relação dialógica entre os indivíduos que podem estar em contextos diferentes, conforme discorre Rancière.

Acreditando nessa possibilidade e trabalhando seriamente em si mesmo para sair de algumas crenças educacionais limitantes como as acepções pessoais de que "não sou capaz de aprender sem a presença do professor ou sem estar na escola", "não consigo compreender assuntos complexos sem explicações extras", existem pessoas que são "inteligentes e outras que são burras" ou ainda, no pensamento que o acesso ao conhecimento requer linearidade e acúmulo de informações. Sobre isso, Rancière discorre:

A emancipação intelectual é a comprovação da igualdade das inteligências. Esta não significa igual valor de todas as manifestações da inteligência, mas igualdade em si da inteligência em todas as suas manifestações. Não há dois tipos de inteligência separados por um abismo. $O$ animal humano aprende todas as coisas como aprendeu a língua materna, como aprendeu a aventurar-se na floresta das coisas e dos signos que o cercam, a fim de assumir um lugar entre os seres humanos: observando e comparando uma coisa com outra, um signo com um fato, um signo com outro signo. (RANCIÈRE, 2010, p. 14-15).

Em sua obra, O Mestre Ignorante, Rancière trata do caso de um educador chamado Jacotot que viveu no período iluminista francês e teria desenvolvido um método próprio de ensino que mais tarde veio a se chamar método emancipador da educação. Segundo Jacotot, qualquer um pode vir a aprender o que quiser, mesmo 


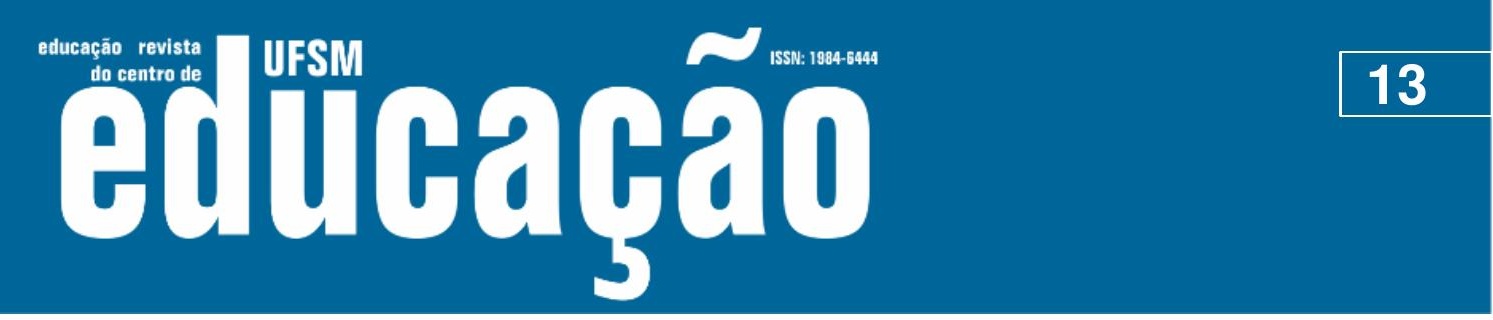

ISSN: 1984-6444 | http://dx.doi.org/10.5902/1984644445284

como função principal conduzir os estudantes à própria ciência, instigando-os a usar a inteligência. Mais que isso, os discentes tornam-se corresponsáveis pelo processo educacional. Além de usar a tecnologia a favor da aprendizagem, a Sala de Aula Invertida apresenta uma mudança de paradigma em que alunos e professores assumem posições desafiadoras assumindo um novo perfil, sobre isso Paulo Freire discorre:

\footnotetext{
Estimular a pergunta, a reflexão crítica sobre a própria pergunta, o que se pretende com esta ou com aquela pergunta em lugar da passividade em face das explicações discursivas do professor, espécies de resposta a perguntas que não foram feitas. [...]. O fundamental é que professor e alunos saibam que a postura deles, do professor e dos alunos, é dialógica, aberta, curiosa, indagadora e não apassivada, enquanto fala ou enquanto ouve. $O$ que importa é que professor e alunos se assumam epistemologicamente curiosos (FREIRE, 2002, p. 33).
}

De acordo com Miskulin (1999), esse processo de renovação sugere uma reorganização dos conteúdos trabalhados, uma transformação de metodologias pedagógicas, redefinição de teorias de ensino, um novo papel da instituição em relação à sociedade e, portanto, uma nova postura do docente já que ressignifica o seu papel dos atores envolvidos no processo de ensino e aprendizagem, onde há uma ruptura com a lógica tradicional da aula explicativa e expositiva para uma dinâmica de interação pautada no aprender a aprender, a conhecer, a fazer e a ser (DELORS, 2003). Pode-se ensinar o que se ignora desde que se emancipe o aluno; isso é, que se force o aluno a usar sua própria inteligência (RANCIÈRE, 2010, p.114).

\section{Os pilares da Sala de Aula Invertida sob a perspectiva de Freire e Rancière}

Para que a Sala de Aula Invertida seja efetivada, é necessário que sua prática esteja apoiada em pressupostos que expressem ambientes flexíveis de aprendizagem que colaborem para o aluno aprender no melhor local e horário para ele, apontando para a liberdade de escolha do tempo e espaço. O trabalho do professor na execução desta estratégia é agir sobre a vontade, sendo um orientador do caminho a percorrer, 


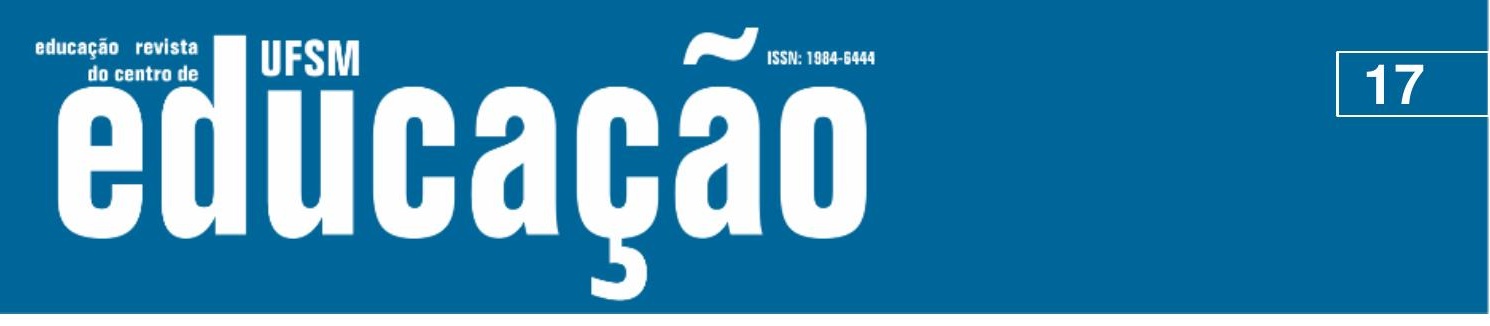

ISSN: 1984-6444 | http://dx.doi.org/10.5902/1984644445284

metas que deseja alcançar e quais os objetivos de aprendizagem esperados. Determina o que deverá ser ensinado e aprendido e quais os recursos necessários para que isto aconteça. Segundo Freire:

\begin{abstract}
Quanto mais progride a problematização, mais penetram os sujeitos na essência do objeto problematizado e mais capazes são de "desvelar" esta essência. Na medida em que a "desvelam", se aprofunda sua consciência nascente, conduzindo assim à conscientização da situação pelas classes pobres. Sua autoinserção crítica na realidade, ou melhor, sua conscientização, faz com que sua apatia se transforme num estado utópico de denúncia e anúncio, um projeto viável (FREIRE, 2018, p. 45).
\end{abstract}

$\mathrm{Na}$ obtenção de êxito na concretização deste pilar, o planejamento é fundamental, bem como contextualizar o que está sendo aprendido, partir de uma situação do cotidiano dos alunos para questões mais complexas com nível de dificuldade mais elaborado. As atividades precisam ser instigantes e terem um fio condutor que propiciem ao aluno aprender de forma autônoma. Os momentos dentro da sala de aula também são de suma importância, pois é o período em que há a socialização das descobertas ou a mostra prática daquilo que se aprendeu. Podemse perceber estes conceitos que reforçam o valor do professor para a autoafirmação do educando nas acepções de Rancière quando nos diz:

\footnotetext{
O que pode, essencialmente, um emancipado é ser emancipador: fornecer, não a chave do saber, mas a consciência daquilo que pode uma inteligência, quando ela se considera como igual a qualquer outra e considera qualquer outra como igual a sua. A emancipação é a consciência dessa igualdade, dessa reciprocidade que, somente ela, permite que a inteligência se atualize pela verificação. O que embrutece o povo não é a falta de instrução, mas a crença na inferioridade de sua inteligência. (RANCIÈRE, 2010 p. 50)
}

Rancière demonstra a maneira pela qual o seu método pode vir a se perpetuar, já que todo aquele que se emancipa pode emancipar outro e assim progressivamente. Dessa forma, o método não precisa de mestres sapientes para ser efetivo; basta encontrar as chaves emancipadoras do processo. Professores do modelo de educação invertida preocupam-se continuamente sobre como eles podem ajudar os alunos a desenvolver o entendimento de conceitos, como também na sua capacidade de atuar com eles em parceria, sem hierarquização do conhecimento. 


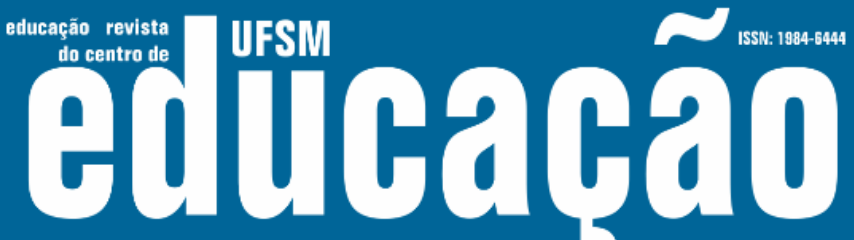

ISSN: 1984-6444 | http://dx.doi.org/10.5902/1984644445284

do conteúdo estudado, isto posto, o mundo passa a ser compreendido como uma rede de inter-relações dinâmicas.

A ampliação da visão do estudante contribui para ampliar a maneira como vemos e a relação que temos com o universo, exaltando os potenciais humanos de intuir, se emocionar e criar, da mesma maneira que a habilidade racional, lógica e verbal. Enfim, a Sala de Aula Invertida oportuniza a conexão entre o homem e o conhecimento com todas as suas sutilezas e potencialidades, a serviço da manutenção do equilíbrio em que cada indivíduo é capaz de aprender, construindo o seu conhecimento.

$\mathrm{Na}$ autonomia do aprendizado, o aluno, de posse do conhecimento pode ver, rever, onde, quando e quantas vezes forem necessárias, os materiais disponíveis no meio digital, diferente do que ocorre com a aula presencial. O educando tem controle sobre seu material e seu aprendizado, inclusive se ele já souber o que está sendo falado, não precisará ouvir/ver tudo de novo. O aluno faz o seu caminho ao conhecimento, do mesmo modo que o princípio da emancipação defendida por ambos os autores. Nessa perspectiva, o "educador já não é o que apenas educa, mas o que, enquanto educa, é educado, em diálogo com o educando que, ao ser educado, também educa" (FREIRE, 2002, p. 61-78).

A autonomia do aprendizado dialoga com os conceitos de emancipação e conscientização propalados por Freire, bem como a ideia da igualdade das inteligências defendida por Ranciére, pois não há saber mais ou saber menos, mas saberes diferentes e, a vontade de aprender funciona como uma potência que possibilita a emancipação pelo conhecimento conquistado. Logo, a aprendizagem da assunção do sujeito é incompatível com o treinamento pragmático ou com o elitismo autoritário dos que se pensam donos da verdade e do saber articulado (FREIRE, 2002, p. 42). Aprendizes e mestres dialogam de forma horizontal, sem empoderamentos ou relação de hierarquização, o conhecimento corre de forma fluída, como uma consequência do esforço coletivo entre alunos e professores em prol de objetivos comuns.

Sobre isso, Rancière provoca a reflexão para o equívoco de pensar que a educação é doses de ensino ao chamado ignorante ou não educado. A igualdade, no 


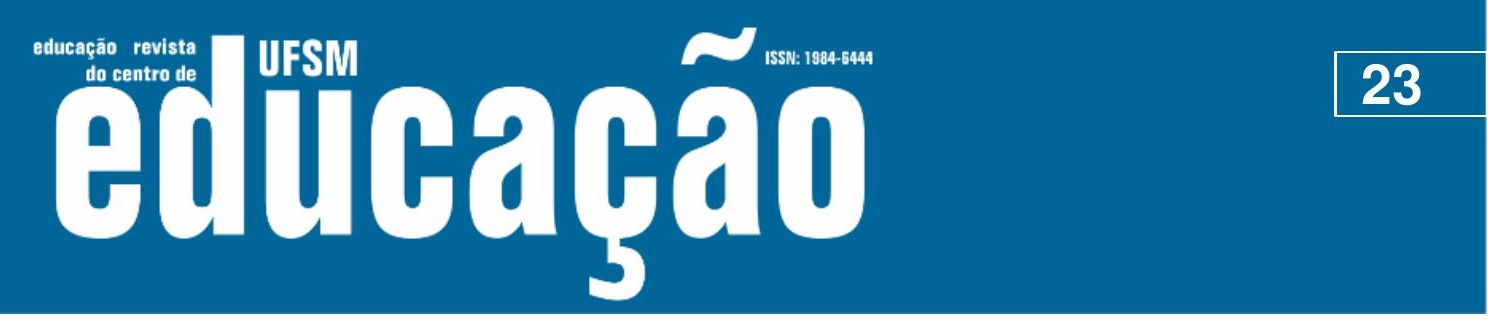

ISSN: 1984-6444 | http://dx.doi.org/10.5902/1984644445284

com a atividade realizada pela centralidade ao aluno que a Sala de Aula Invertida oportuniza.

\section{Referências}

ALMEIDA, M. E. B. Integração de currículo e tecnologias: a emergência de web currículo. Anais do XV Endipe - Encontro Nacional de Didática e Prática de Ensino. Belo Horizonte: UFMG, 2012.

BARBOSA, Eduardo Fernandes; MOURA, Dácio Guimarães de. Metodologias ativas de aprendizagem na Educação Profissional e Tecnológica. B.Tec. Senac, Rio de Janeiro, v.39, n.2, p.48-67, 2013.

BRASIL. Ministério da Educação. Parâmetros Curriculares Nacionais. Brasília: MEC/SEF, p.1-23, 2000.

BERGMANN, J.; SAMS, A. Sala de aula invertida - uma metodologia ativa de aprendizagem. 1. ed. Rio de Janeiro. 2016.

COTTA, Rosângela Minardi Mitre; SILVA, Luciana Saraiva da; LOPES, Lílian Lelis; GOMES, Karine de Oliveira; COTTA, Fernanda Mitre; LUGARINHO, Regina; MITRE, Sandra Minardi. Construção de portfólios coletivo em currículos tradicionais: uma proposta inovadora de ensino-aprendizagem. Ciência \& Saúde Coletiva. v.3, n.17, p.787-796, 2012.

DELORS, Jacques. Educação: um tesouro a descobrir. 2ed. São Paulo: Cortez, 2003.

FREIRE, Paulo. Pedagogia da Autonomia: Saberes necessários a prática educativa. São Paulo: Paz e Terra, 2002.

FREIRE, Paulo. Educação como prática da liberdade. Editora Paz e Terra, 2014.

FREIRE, Paulo. Conscientização. Cortez Editora, 2018.

GATTI, B. A. A construção da pesquisa em educação no Brasil. Brasília: Plano Editora, 2002. Cap. 1, p. 15-39.

GIL, Antônio Carlos. Como elaborar projetos de pesquisa. 4. ed. São Paulo: Atlas, 2002.

JORDÃO, Fabio. História: a evolução do celular, 2009. 


\section{$=-1$ usm \\ 158N: 1884-6444}

ISSN: 1984-6444 | http://dx.doi.org/10.5902/1984644445284

LUCINI, M. Fenomenologia hermenêutica: uma experiência metodológica. In BRETAS, Silvana Aparecida; SOBRAL, M. N. (org.) Pesquisa em educação: Interfaces, experiências e orientações.

MISKULIN, R. G. S. Concepções teórico-metodológicas sobre a introdução e a utilização de computadores no processo de ensino/aprendizagem da geometria. 1999. 273 f. Tese (Doutorado em Educação Matemática) - Faculdade de Educação, Universidade de Campinas, Campinas, 1999.

OLIVEIRA, Y.D. A formulação do problema de pesquisa: considerações sobre uma experiência no âmbito da história da educação. In BRETAS, S. A. e SOBRAL; M. N. (org.) Pesquisa em educação: Interfaces, experiências e orientações. mimeo.

RANCIÈRE, Jacques. O mestre ignorante: cinco lições sobre a emancipação intelectual. Belo Horizonte: Autêntica, 2010.

VERGARA, Sylvia Constant. Projetos e relatórios de pesquisa em administração. 6. ed. São Paulo: Atlas, 2005.

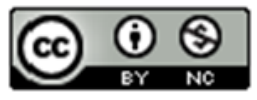

This work is licensed under a Creative Commons Attribution-NonCommercial 4.0 International (CC BY-NC 4.0) 